\title{
0060 WORK-RELATED INJURY AND ILL-HEALTH AMONG MOUNTAINEERS IN THE UK: IDENTIFYING KEY FACTORS
}

H McDermott*, F Munir, D St Laurent Correspondence: Loughborough University, School of Sport, Exercise and Health Sciences Loughborough University Epinal Way Loughborough, Leicestershire, LE11 3TU, UK

10.1136/ip.2010.029215.60

Background Chronic illnesses are recognised as one of the most expensive health problems in industrialised countries. In 2008/2009, an estimated 1.2 million Britons were suffering from an illness they believed was caused or made worse by work. Of these, musculoskeletal disorders and stress were the most common, with those working in some industries more at risk than others. Within the last decade increased levels of participation in adventure activities such as mountaineering has led to an increase in those who lead such activities as a career. The high risk nature of leading adventurous activities may have adverse effects on health, yet very little is known about the cumulative effects of a career in the outdoor industry.

Aims and method This study aimed to identify the key factors related to the physical and psychological health of those working as Mountain Instructors within the UK. Semistructured interviews were conducted with 20 mountaineers to gain information on work-related injury and illhealth.

Results A large number of interviewees reported suffering from a musculoskeletal disorder which was related to work activities and many interviewees felt they had to continue to work even when ill or injured. Examples of work-related issues causing stress were also reported including aggressive or challenging behaviours presented by clients and extended working days.

Conclusion Those working in the outdoor industry develop a variety of chronic injuries. These data informed the development of a large scale questionnaire study, the findings of which will also be discussed. 